\title{
Gender-role Expectations and Fertility Rates in EU Member States
}

\author{
Chyong-fang Ko
}

Academia Sinica, Taiwan

Copyright $\bigcirc 2016$ by authors, all rights reserved. Authors agree that this article remains permanently open access under the terms of the Creative Commons Attribution License 4.0 International License

\begin{abstract}
The author uses data from the European Values Study 2008 to investigate possible links between gender-related attitudes and fertility rates in EU member states. Countries with higher income levels and female employment rates were found to have higher fertility rates, and countries with higher fertility rates tended to have higher percentages of live births outside of marriage, suggesting a significant change in traditional family structure. A positive correlation between gender equity and reduced traditional gender role expectations was observed in wealthier countries, which also had greater female labor force participation and higher fertility rates. In wealthy Western societies, couples no longer have children for purposes of extending family lines or providing support in old age. For many women, children and careers now go hand-in-hand.
\end{abstract}

Keywords Gender-role Expectations, Fertility, Gender Equity, Female Employment, EU

\section{Introduction}

The steady decline in fertility rates worldwide has attracted a great deal of research attention since the 1990s. According to recent UN estimates, 46 percent of the world's population lives in countries with fertility rates at or below replacement level (average 2.1 children per woman), resulting in rapidly aging populations and negative population growth (United Nations [1]). According to demographic data provided by the European Union, total fertility rates (TFRs) for the 28 member states (EU28) in 2014 ranged between 1.23 (Portugal) and 2.01 (France) (Eurostat [2]). Without a large influx of immigrants, one-half of EU28 countries would have had negative population growth in 2015. According to EU projections, between 2015 and 2080 there will be 327.1 million births and 387.2 million deaths in the EU28 - a net reduction of 60.1 million inhabitants (Eurostat [3]). According to Morgan [4], nearly all countries will have low fertility rates within the next two decades. However, Morgan does not view low fertility as a crisis, since it can be addressed and reversed via public policy and institutional adjustments. He describes low fertility as "a problem that befalls developed countries that, by and large, have the resources to respond" (p. 600). If Morgan's assertions are true, many questions arise regarding possible declining fertility scenarios and required adjustments. Two of them involve women holding jobs outside their households and the retention of the "breadwinner model" of traditional gender roles.

The main motivation for this paper is to use survey data from the European Values Study 2008 (EVS2008) to investigate gender-role expectations and associations with fertility rates - that is, to determine whether gender-role expectations are associated with fecundity. In countries with greater gender equity, women are not expected to stay at home to raise children and manage household affairs, but to pursue advanced educations and careers. There are some expectations that "pronatalist policies" such as affordable childcare and flexible working hours (especially for dual-wage earner families) will result in higher fertility rates.

\section{Literature Review}

Mason [5] claims that none of the many theories of fertility transition (i.e., long-term declines in the number of childbirths from four or more per woman to two or fewer) provide a comprehensive explanation for declines in fertility below replacement level. She acknowledges that one "grand theory" is highly unlikely to emerge, since fertility transitions occur under a variety of institutional, cultural, and environmental conditions. Manson also argues that the decline in mortality associated with socioeconomic development is a critical precondition resulting in falling fertility rates. In other words, in countries where mortality rates for children are high, couples are likely to have more children to make sure that one or two survive, and in countries where mortality rates for children are low, couples will give birth to fewer children.

Using data from interviews with 50 dual-wage earner 
families in the San Francisco Bay area, Hochschild [6] argues that only "luckier" women can successfully hold jobs while raising families. Using her own experience as an example, she raised two children while teaching at the University of California at Berkeley. Her job provided flexible working hours and an amicable environment for nursing and caring for her infants. However, she observes that most American working women are not equally fortunate, since they bear the burden of what she calls a "stalled revolution." While a large percentage of American women hold jobs for their own fulfillment or economic necessities for their families, they must be willing to work two "shifts," with the second aimed at taking care of child-raising and household responsibilities. According to Hochschild, most men and women enter marriage with traditional gender ideologies in which wives/mothers suffer the most from balancing work and family duties. McDonald [7] argues that under such circumstances, women are more likely to consciously decide to not have children, or to have fewer children than they originally intended.

Bumpass [8] asserts that the high costs of childrearing - especially opportunity costs tied to the incompatibility of work and family obligations for women in industrial and postindustrial economies - are the driving force behind low fertility rates. Using data from 22 low-fertility countries, Rindfuss et al. [9] found a negative association between TFRs and female labor force participation rates between 1960 and the early 1980s (correlation coefficients between 0 and -0.8). This association became positive in the late 1980 s, and strongly positive in the 1990s (correlation coefficients as high as 0.6). Myrskylä et al. [10] identified a J-shaped relationship between TFR and Human Development Index (HDI) data for 1975 and 2005, leading them to suggest a negative association between TFR and HDI at low and medium HDI levels $(<0.85-0.9)$, but positive associations at higher HDI levels $(>0.85-0.9)$.

Chesnais [11] has observed that in advanced countries, many women have education and employment opportunities that are nearly equal to those of men, but those opportunities are severely curtailed by decisions to have children, resulting in long-term low fertility rates. McDonald [7, 12] claims that low fertility in advanced countries can be explained in terms of incoherence between gender equity levels across various social institutions. Using Southern European and advanced East Asian countries as examples, he notes that institutional support for work-family combinations is poorly developed, resulting in fertility rates at or below 1.5 per female. In contrast, fertility is relatively high in France and Nordic countries, since they have family policy regimes in place that support women's efforts to combine work and family.

\section{Data and Methods}

Data from the fourth wave of EVS2008 were used to identify gender equity and gender-role expectations for residents of European countries. The EVS is a large-scale longitudinal survey focused on human values. The first EVS was conducted in 1981. Additional data collection has taken place once every nine years since, with an increasing number of participating countries. More than 70,000 citizens living in 46 countries were interviewed for EVS2008. A random sample of 1,500 persons age 15 and older was created for each country, with participants sharing their opinions during personal interviews.

A main premise of this paper is that attitudes toward gender equity and gender roles in EU28 nations are considered culture-specific. In an effort to ensure that all interviewees from the same countries shared similar cultural backgrounds, 6,037 respondents whose fathers and mothers were not born in their current countries were excluded, resulting in a sample of 35,953 . The majority of respondents were female (56\%), mean respondent age was 49 , and more than half had at least a high school education.

Responses to three EVS2008 items were used to measure gender equity, gender-role expectations, and institutional adjustment:

1. Gender equity. This item was worded as "When jobs are scarce, men have more right to a job than women: (1) agree, (2) disagree, (3) neither, (4) don't know, (5) no answer." Percentages of "agree" responses were viewed as indicating degree of gender equity on a country level. Higher values indicate lower gender equity.

2. Gender-role expectations. This was measured by the item, "Do you think that a woman has to have children in order to be fulfilled, or is this not necessary? (1) needs children, (2) not necessary, (3) don't know, (4) no answer." "Needs children" response percentages were viewed as indicators of gender-role expectations, with higher values indicating higher expectations to fulfill traditional gender roles.

3. Institutional adjustment. This was measured by the item, "A pre-school child is likely to suffer if his or her mother works: (1) agree strongly, (2) agree, (3) disagree, (4) disagree strongly, (8) don't know, (9) no answer." Summed "agree strongly" and "agree" percentages were used as indicators of institutional adjustment. It was assumed that certain kinds of institutional adjustment (e.g., affordable child care policies and flexible working hours for parents) would mitigate suffering felt by preschool-aged children whose mothers work outside the home. Accordingly, lower percentages indicate higher degrees of institutional adjustment.

In addition to EVS2008 survey data, country-level data (TFR, GNI Per Capita, and HDI) were also used to investigate their various links with gender-related attitudes. Since EVS2008 data were collected between 2008 and 2009, TFR 2008, GNI 2008 and HDI 2007 data were used for comparative purposes.

\section{Findings}

As indicated by Eurostat [13] statistics, the combined population of EU28 countries was slightly more than 500 
million in 2008. Current estimates are that this number will increase 5 percent by 2050, from 500.3 to 525.5 million [14]. Most population growth in individual EU nations during the past decade has been the result of in-migration - 859,275 migrants between 2008 and 2009, which is 63 percent of the overall population increase of $1,369,058$ for those two years. Similar patterns were noted for all EU28 countries with the exceptions of Germany, Ireland, Cyprus, Malta and five Eastern European countries (Bulgaria, Poland, Romania, Latvia and Lithuania). In these countries, the number of out-migrants exceeded in-migrants, and deaths exceeded births. Without large numbers of immigrants, the populations of Italy, Austria and Portugal would have decreased between 2008 and 2009 (European Commission [15]).

A country's total fertility rate must exceed 2.1 - replacement level - to maintain a steady population size. According to Eurostat statistics, none of the $28 \mathrm{EU}$ member states reached this level in 2008, meaning that they are all experiencing negative population growth [2]. Fertility rate statistics for 2008 indicate that France and Ireland were at the top of the list, and Slovakia and Hungary at the bottom. Note that fertility rates were higher overall in Scandinavian countries (where non-traditional families are more common) than in countries such as Italy, Spain and Portugal (which are known for more conservative attitudes toward families).

As shown in Figure 1, a positive association was found between TFR and HDI $(r=0.48)$ in EU28 countries, a result that supports Myrskylä et al.'s [9] finding of a positive association between TFR and HDI in countries where the HDI exceeded 0.85. Among EU28 states, all HDI values for individual countries were above 0.85 , except for Romania (0.837) and Bulgaria (0.840). Since HDI is strongly associated with GNI $(\mathrm{r}=0.86)$, we also predicted a positive association between TFR and GNI ( $\mathrm{r}=0.44)$. These results indicate that EU member states with higher GNI and/or HDI values tended to have higher fertility rates. They also support Morgan's conclusion that developed countries have the necessary resources to respond to falling fertility rates.

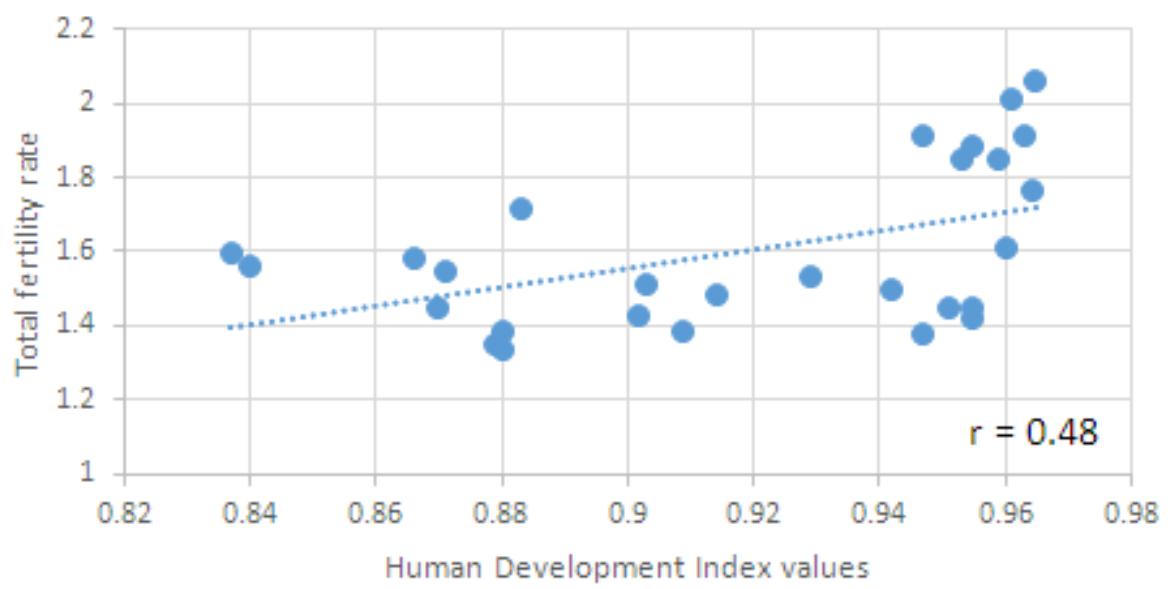

Figure 1. Total fertility rate data plotted against Human Development Index values

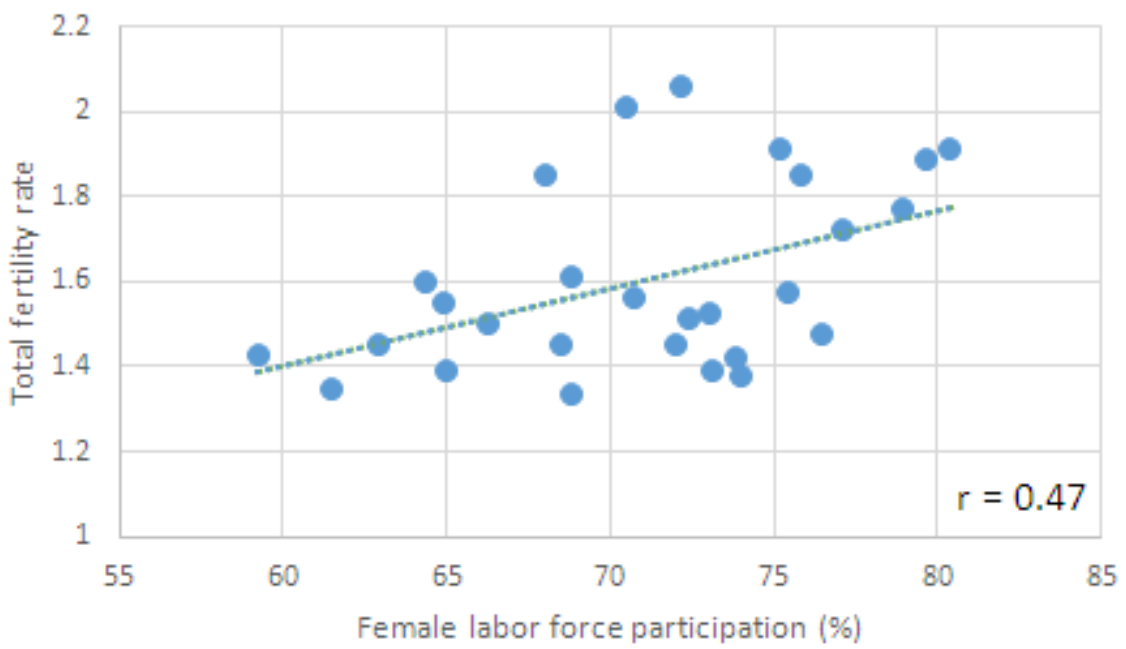

Figure 2. Total fertility rate data plotted against female labor force participation percentages

As suggested in an earlier section, we expected that developed countries would have greater female labor force participation, lower levels of traditional gender-role expectations, and higher levels of gender equity. As shown in Figures 2 
through 4, TFR was positively associated with female labor force participation $(\mathrm{r}=0.47)$ and negatively associated with both gender-based inequity $(\mathrm{r}=-0.55)$ and traditional gender role expectations $(\mathrm{r}=-0.44)$. These results are consistent with previous research findings. We also observed a negative association between gender inequity and both GNI $(\mathrm{r}=-0.44)$ and HDI $(\mathrm{r}=-0.37)$. Negative associations were also noted between gender-role expectations and both GNI ( $\mathrm{r}=-0.64)$ and HDI $(\mathrm{r}=-0.65)$. Women's attitudes toward childrearing and careers are frequently cited in analyses of countries where fertility rates are low. However, our data suggest that in relatively well-developed countries with higher levels of gender equity, women are more likely to simultaneously hold jobs and raise children.

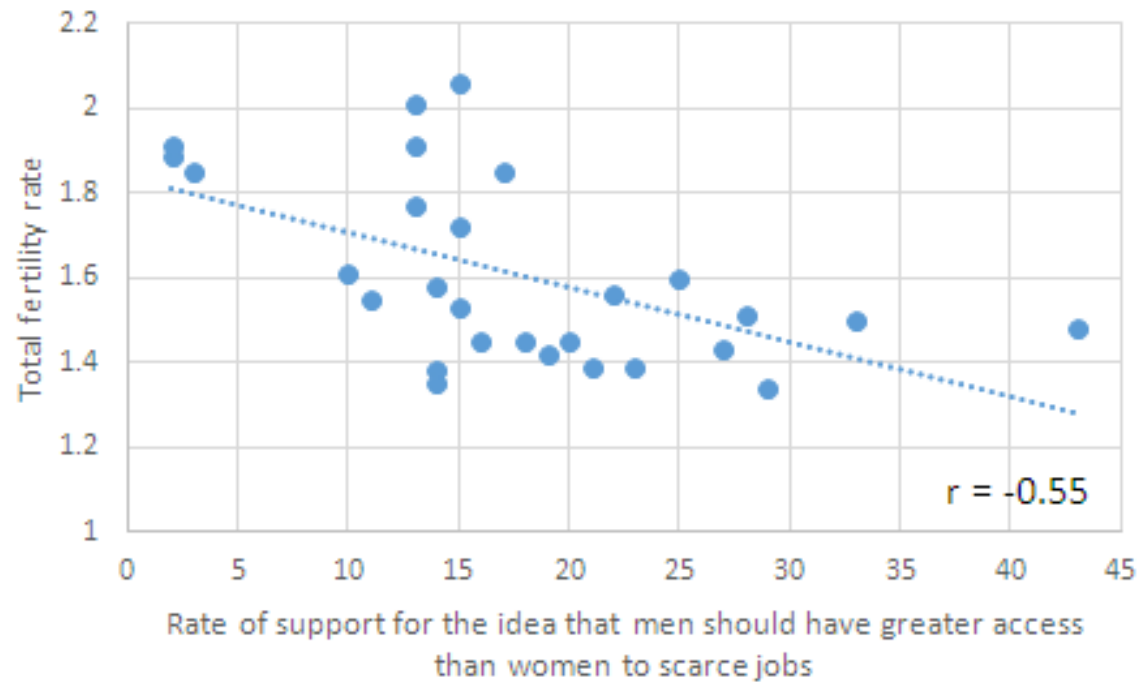

Figure 3. Total fertility rate data plotted against rate of support for the idea that men should have greater access than women to scarce jobs

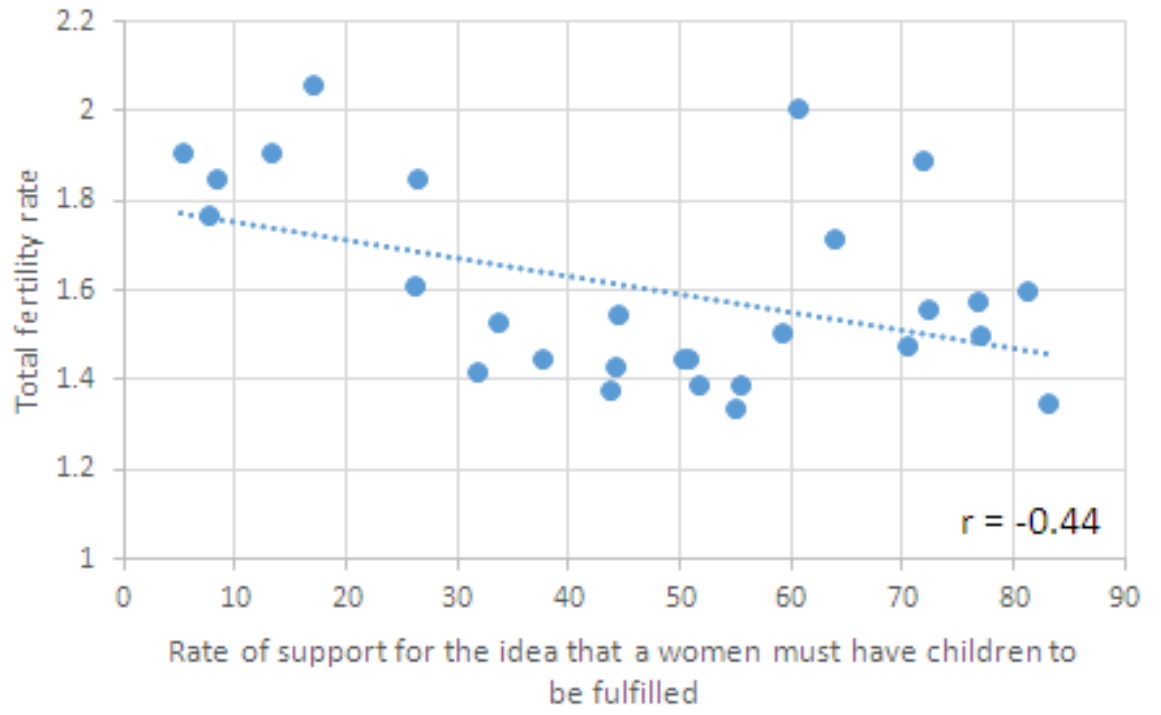

Figure 4. Total fertility rate data plotted against rate of support for the idea that a woman must have children to be fulfilled

Some researchers have suggested that pronatalist policies can encourage dual-wage earner families to have more children. For the present study we assumed that pronatalist policies such as affordable child care and flexible work hours promote work-family coherence, thus weakening the impression that pre-school children may suffer if their mothers work outside the home. As shown in Figure 5, a negative association was found between TFR and the level of support for this idea $(\mathrm{r}=-0.68)$ - a finding that implies a lack of supportive childcare policies and/or institutional adjustments associated with fertility rates. 


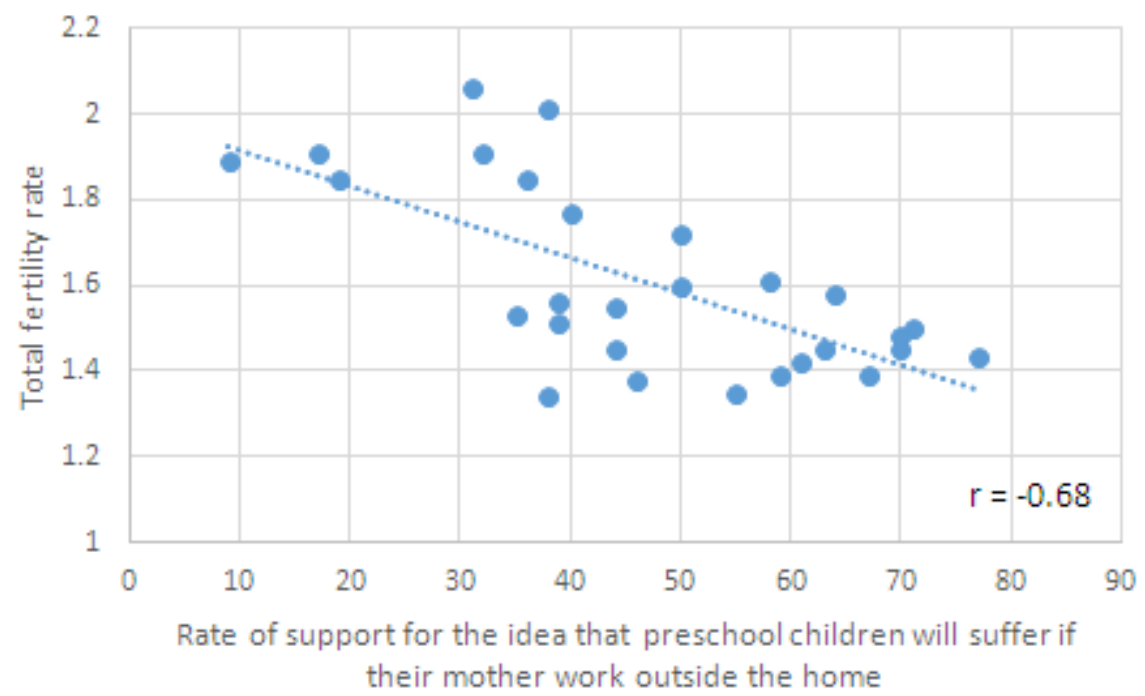

Figure 5. Total fertility rate data plotted against rate of support for the idea that preschool children will suffer if their mothers work outside the home

We found positive associations between percentage of live births outside of marriage and both TFR ( $\mathrm{r}=0.50$, Figure 6 ) and female labor force participation ( $\mathrm{r}=0.60$, Figure 7). Instead of interpreting this finding in terms of single parenthood or (un)expected births among cohabiting couples, it may be an indicator of institutional adjustment toward a more positive environment for women wanting to simultaneously pursue careers and parenthood.

In order to examine the impacts of gender-related factors on TFR, all explanatory variables were included in an OLS regression analysis. As shown in Table 1 (Model 1), none of the independent variables were significant at a P-value of 0.05 . However, HDI and the assumption that pre-school children will suffer if their mothers work outside the home were the two most significant factors (respective standardized regression coefficients of 0.28 and -0.44). As shown in Table 1, Model 2 was found to be a better fit - that is, it confirmed the importance of social development (as indicated by HDI) and institutional adjustments (as indicated by the impression that pre-school children will suffer if their mothers work outside the home) in promoting fertility rates (standardized regression coefficients of 0.29 and -0.44 , respectively).

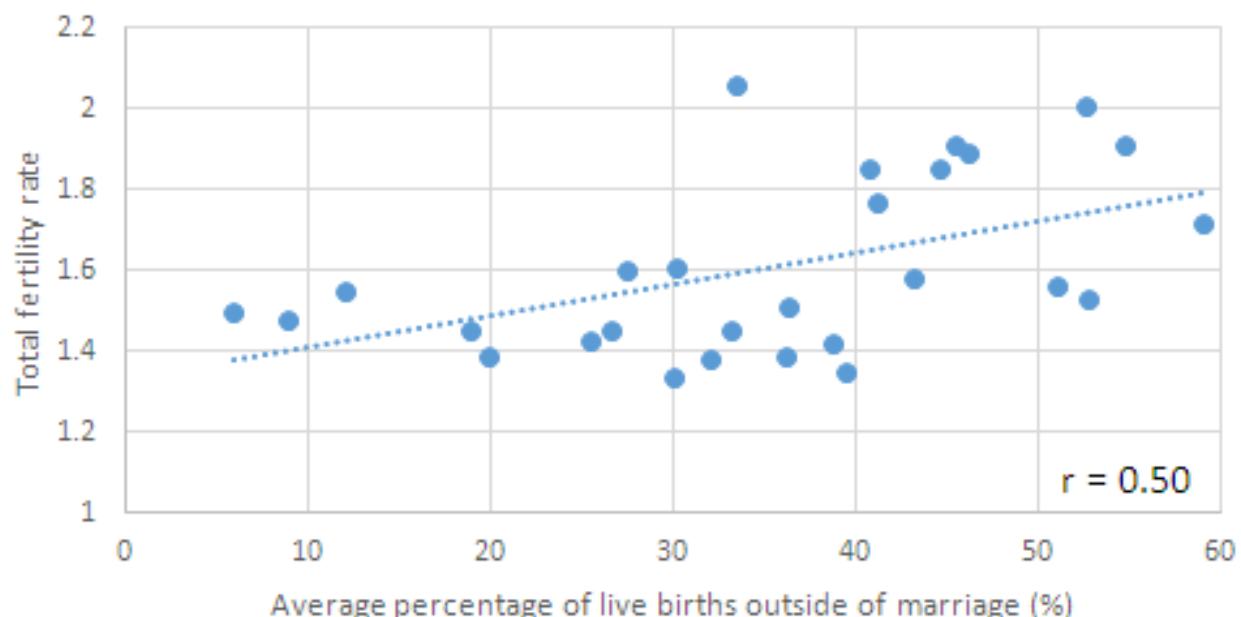

Figure 6. Total fertility rate data plotted against average percentage of live births outside of marriage 


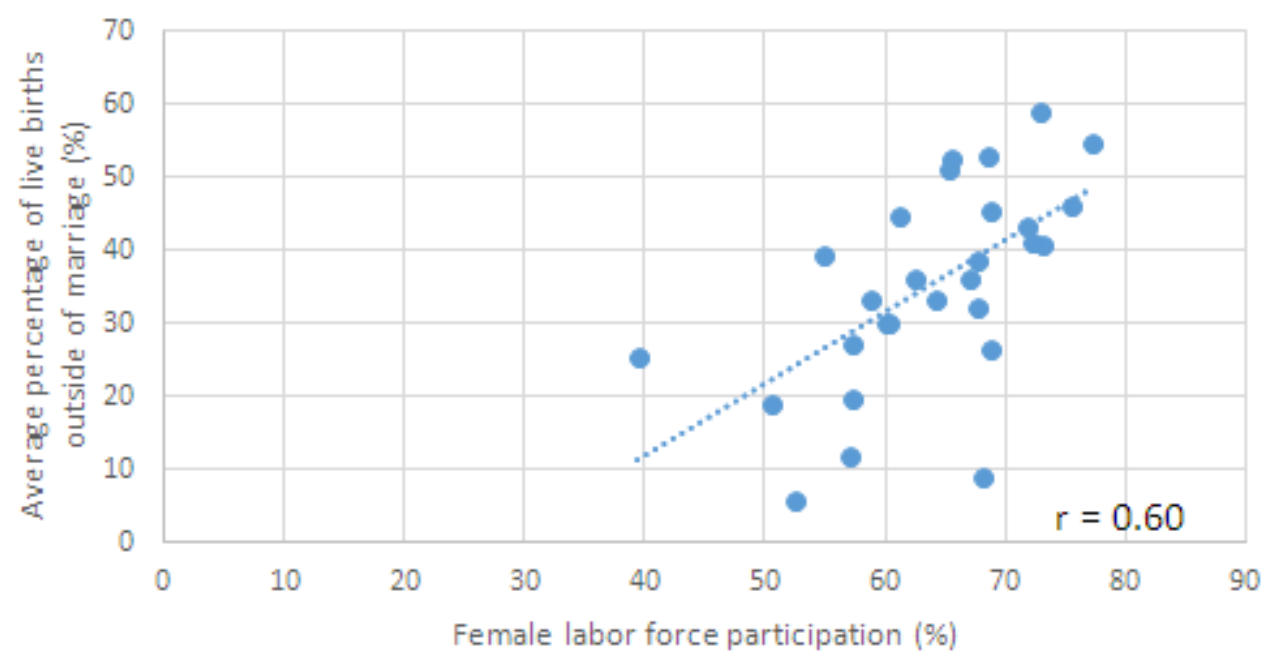

Figure 7. Average percentage of live births outside of marriage data plotted against female labor force participation percentages

Table 1. OLS regression results for total fertility rates in EU member states.

\begin{tabular}{|c|c|c|c|c|}
\hline & \multicolumn{2}{|c|}{ Model 1} & \multicolumn{2}{|c|}{ Model 2} \\
\hline Variable & $\begin{array}{c}\text { Parameter } \\
\text { Estimate } \\
\text { (standardized } \\
\text { estimate) }\end{array}$ & $\begin{array}{l}\text { Standard } \\
\text { Error } \\
(\operatorname{Pr}>|t|)\end{array}$ & $\begin{array}{c}\text { Parameter } \\
\text { Estimate } \\
\text { (standardized } \\
\text { estimate) }\end{array}$ & $\begin{array}{l}\text { Standard } \\
\text { Error } \\
(\operatorname{Pr}>|t|)\end{array}$ \\
\hline Intercept & $\begin{array}{c}0.38 \\
---\end{array}$ & $\begin{array}{c}1.05 \\
(0.7218)\end{array}$ & $\begin{array}{c}0.55 \\
--\end{array}$ & $\begin{array}{c}0.72 \\
(0.4537)\end{array}$ \\
\hline HDI & $\begin{array}{c}1.48 \\
(0.28)\end{array}$ & $\begin{array}{c}1.00 \\
(0.1558)\end{array}$ & $\begin{array}{c}1.52 \\
(0.29)\end{array}$ & $\begin{array}{c}0.75 \\
(0.0547) \\
\end{array}$ \\
\hline Men should have greater access to scarce jobs & $\begin{array}{l}-0.001 \\
(-0.04)\end{array}$ & $\begin{array}{c}0.005 \\
(0.8394)\end{array}$ & --- & --- \\
\hline $\begin{array}{l}\text { Pre-school children will suffer if mothers work } \\
\text { outside the home }\end{array}$ & $\begin{array}{l}-0.005 \\
(-0.44)\end{array}$ & $\begin{array}{c}0.003 \\
(0.0538) \\
\end{array}$ & $\begin{array}{l}-0.007 \\
(-0.58) \\
\end{array}$ & $\begin{array}{c}0.002 \\
(0.0005) \\
\end{array}$ \\
\hline Women need children to be fulfilled & $\begin{array}{r}-0.0001 \\
(-0.01) \\
\end{array}$ & $\begin{array}{c}0.002 \\
(0.9594) \\
\end{array}$ & --- & --- \\
\hline Female labor force participation rate & $\begin{array}{l}0.001 \\
(0.05) \\
\end{array}$ & $\begin{array}{c}0.005 \\
(0.8152) \\
\end{array}$ & --- & --- \\
\hline Live births outside of marriage & $\begin{array}{l}0.002 \\
(0.14)\end{array}$ & $\begin{array}{c}0.003 \\
(0.5041)\end{array}$ & --- & --- \\
\hline $\mathrm{N}$ & 28 & & 28 & \\
\hline $\mathrm{R}^{2}$ & 0.56 & & 0.54 & \\
\hline
\end{tabular}

\section{Conclusions}

The motivation for this paper was to use data from the European Values Study 2008 to investigate gender ideologies and associations with fertility rates in EU member states. Among the $28 \mathrm{EU}$ countries included in the EVS2008 report, Ireland and France had the highest fertility rates, and Hungary and Slovakia the lowest. Countries with higher HDI and/or per capita GNI values and higher female employment rates tended to have higher fertility rates. Countries with higher fertility rates tended to have higher percentages of live births outside of marriage. Further analysis reveals associations between fertility and gender-related attitudes. Countries with higher levels of gender equity tend to have lower traditional gender-role expectations and more family-friendly arrangements that result in higher fertility rates. Data from an OLS regression analysis indicate that two factors were most effective in explaining the variance in total fertility rates across EU member states: HDI, and the idea that pre-school children will suffer if mothers work outside the home $\left(\mathrm{R}^{2}=0.54\right)$.

In summary, our findings suggest that fertility behaviors cannot be explained by individual factors alone, and that structural factors are significant. Until the mid-twentieth century, men were encouraged to work outside the home while women managed households and raised children. Currently the breadwinner model is being replaced by significant female labor force participation for financial or self-fulfillment reasons. Several factors have been cited as having the potential to reverse steady declines in fertility rates, especially changes in personal attitudes, social values, and policies that help women to reconcile paid work with household responsibilities (e.g., child care, flexible working hours, pension reforms, and other financial incentives). 


\section{REFERENCES}

[1] United Nations. Department of Economic and Social Affairs. 2015. World Population Prospects: 2015 Revision. Available from: http://esa.un.org/unpd/wpp/ [Accessed 12th September 2016]

[2] Total fertility rate [Internet]. Appsso.eurostat.ec.europa.eu. 2016 [cited 12 September 2016]. Available from: http://appsso.eurostat.ec.europa.eu/nui/submitViewTableAct ion.do

[3] Migrant population [Internet]. Appsso.eurostat.ec.europa.eu. 2016 [cited 12 September 2016]. Available from: http://ec.europa.eu/eurostat/statistics-explained/index.php/Mi gration_and_migrant_population_statistics

[4] Morgan SP. Is low fertility a twenty-first-century demographic crisis? Demography. 2003; 40(4):589-603.

[5] Mason KO. Explaining fertility transitions. Demography. 1997; 34(4):443-54.

[6] Hochschild A, Machung A. The second shift: Working families and the revolution at home: Penguin; 2012.

[7] McDonald P. Societal foundations for explaining fertility: Gender equity. Demographic Research. 2013; 28: 981-94.

[8] Bumpass LL. What's happening to the family? Interactions between demographic and institutional change. Demography. 1990; 27(4):483-98.

[9] Rindfuss RR, Guzzo KB, Morgan SP. The changing institutional context of low fertility. Population Research and Policy Review. 2003; 22(5-6):411-38.

[10] Myrskylä M, Kohler H-P, Billari FC. Advances in development reverse fertility declines. Nature. 2009; 460(7256):741-3.

[11] Chesnais J-C. Fertility, family, and social policy in contemporary Western Europe. Population and Development review. 1996:729-39.

[12] McDonald P. Gender equity, social institutions and the future of fertility. Journal of the Australian Population Association. 2000; 17(1):1-16.

[13] Total population [Internet]. Appsso.eurostat.ec.europa.eu. 2016 [cited 12 September 2016]. Available from: http://ec.europa.eu/eurostat/tgm/table.do?tab=table\&init=1\& language $=$ en $\&$ pcode $=$ tps $00001 \&$ plugin $=1$

[14] Population projection [Internet]. Appsso.eurostat.ec.europa.e u. 2016 [cited 12 September 2016]. Available from: http://ap psso.eurostat.ec.europa.eu/nui/show.do?dataset $=$ proj_13npm s\&lang=en

[15] European Union. Key facts and figures about Europe and the Europeans. Available from: http://ec.europa.eu/publications/ booklets/eu glance/66/index en.html [Accessed 15th August 2016]. 